\title{
Figuras do baile: pictogramas para o fortalecimento da identidade dos grupos de reisado do Cariri
}

\author{
Dancing figures: pictograms for the strengthening of the identity of the Cariri reissue \\ groups
}

\author{
Cicero Reginaldo Farias da Silva, Débora Rodrigues dos Santos \& Manoel Deisson \\ Xenofonte de Araújo
}

design gráfico, pictograma, tradição popular, reisado de congo.

\begin{abstract}
$\mathrm{Na}$ linguagem visual, os pictogramas traduzem conceitos e objetos com simplificação sem perder o significado essencial do que se está representando. Usados com grande abrangência na sinalização, seu uso pode ser utilizado para uma infinidade de aplicações. Por essa facilidade de aplicação e leiturabilidade simples e objetiva, os pictogramas foram utilizados nesse projeto, como sinais pictóricos representativos dos grupos de reisado. Dos vários tipos de reisado encontrados no nordeste, optou-se pelo Reisado de Congo, existentes em vários bairros periféricos da cidade de Juazeiro do Norte, interior do Ceará. Na margem dessa cidade, o reisado ajuda a ler e escrever a trama histórica dessa cidade mítica criado pelo Padre Cícero, montando uma rede de memórias da tradição do seu povo. Para fortalecer essa relação, os pictogramas vem para valorizar e divulgar a identidade desses coletivos e prever algumas aplicações para se uso na comunicação visual.
\end{abstract}

graphic design, pictogram, popular tradition, congo reisado.

In visual language, pictograms translate concepts and objects with simplification without losing the essential meaning of what is being represented. Used with wide scope in signaling, its use can be used for a plethora of applications. Because of this ease of application and simple and objective readability, the pictograms were used in this project, as representative pictorial signs of the reisado groups. Of the various types of reisado found in the northeast, the Reisado de Congo was chosen, existing in several peripheral districts of the city of Juazeiro do Norte, interior of Ceará. On the bank of this city, the reisado helps to read and write the historical plot of this mythical city created by Father Cicero, setting up a network of memories of the tradition of his people. To strengthen this relationship, pictograms come to value and publicize the identity of these collectives and provide some applications for use in visual communication.

\section{Introdução ou abrição de portas}

Na linguagem visual, os pictogramas traduzem conceitos e objetos com simplificação sem perder o significado essencial do que se está representando, por essas características são largamente utilizados em projetos de sinalização. Comumente são usados como sinais que trazem informação de utilidade ou advertência, que possa ser compreendida a nível universal, independente do idioma, escolaridade etc.

Nesse sentido tomaremos como objeto de estudo os grupos de reisado da cidade de Juazeiro do Norte - território de múltiplas práticas, um lugar onde a cultura nordestina e sua religiosidade se apresentam. A cidade, além de ser conhecida por sua religiosidade é um importante centro cultural. Nela existem vários grupos de tradição popular (reisado, maneiropau, malhação de Judas, entre outros).

Com inspiração nos projetos de "Infografia na Cozinha", de Mariana Salema e "Mini Rio", de Fábio Lopes, buscou-se reunir dados/informações para o desenvolvimento de pictogramas baseados em elementos da cultura popular, para representar os grupos de reisado, auxiliando na valorização da identidade desses grupos.

Anais do $9 \%$ CIDI e 9 CONGIC

Luciane Maria Fadel, Carla Spinillo, Anderson Horta,

Cristina Portugal (orgs.)

Sociedade Brasileira de Design da Informação - SBDI

Belo Horizonte | Brasil | 2019

ISBN 978-85-212-1728-2
Proceedings of the 9th CIDI and 9th CONGIC

Luciane Maria Fadel, Carla Spinillo, Anderson Horta, Cristina Portugal (orgs.)

Sociedade Brasileira de Design da Informação - SBDI

Belo Horizonte | Brazil | 2019

ISBN 978-85-212-1728-2 
O objetivo geral dessa pesquisa consiste em desenvolver um conjunto de pictogramas a partir dos elementos dos grupos de reisado, de modo a representar uma identidade, que possa comunicar visualmente esses grupos de tradição. Como objetivos específicos, citamos: analisar as características identitárias do reisado de Juazeiro do Norte; desenvolver pictogramas a partir da análise realizada; sugerir aplicações dos pictogramas em diferentes produtos e sinalizações.

\section{Referencial teórico ou batalhas}

\section{Cidade, memória, cultura e imaginário}

Com histórias e identidades singulares, a cidade se mostra plural no que se referem às suas relações e manifestações que podem favorecer a construção ou fortalecimento de identidades.

A cidade fala a seus habitantes e a seus visitantes através dos nomes próprios que ela abriga (ruas, edifícios, monumentos). O grande texto urbano tece dentro de si uma miríade de outros textos, construídos de placas de ruas que evocam memórias e imaginários, de cartazes que são expostos nas avenidas seduzindo e informando e também das pequenas conversas produzidas nos encontros cotidianos. (Barros, 2007)

Para Morigi, Rocha e Semensatto (2012), a transmissão da tradição, ancorada nas lembranças e aprendizados passados que se alojam na memória individual e coletiva, através da experiência socialmente compartilhada, é relevante para a continuidade da cultura local e como produtora de sentidos compartilhados e construtora daquilo que reconhecemos como parte da cultura humana.

Portanto, a memória coletiva é construção de laços sociais, caracterizada por um intenso componente afetivo que surge da interação e das experiências entre os membros da comunidade, envolve sentimentos de pertença e identidade, já que a memória é sempre dependente das interações e dos grupos sociais. A memória emerge nos grupos e em seus rituais através da afirmação de suas tradições, da manutenção e da atualização de suas significações, confrontando o passado no presente. (Morigi, Rocha \& Semensatto, 2012). Nessa medida, ela é importante para manter a integridade e a sobrevivência do grupo no tempo (Halbwachs, 1990). Cabe dizer que a força da memória não se deve a sua origem social, e sim a sua possibilidade de ser compartilhada por todos e fortalecida pela tradição.

Clifford Geertz (1989), um dos expoentes do entendimento da Cultura como um sistema simbólico, (Laraia, 2006), considera que esta diz respeito à produção e elaboração, simbólica e material, do ser humano: os artefatos, o imaginário, os comportamentos, as práticas; as formas de expressão, de organização, de percepção e de apropriação do cotidiano.

O imaginário, no entanto, é uma força social de ordem espiritual, uma construção mental, que se mantém ambígua, perceptível, mas não quantificável. É a cultura de um grupo, é a aura que o alimenta e é, também, criador de um conjunto de símbolos, imagens oníricas, lúdicas, imaginativas, afetivas, potencializadoras das práticas.

Sem a cultura, não haveria o homem, mas de forma semelhante a cultura não existiria sem ele. Não pode haver realidade social sem o homem, ao passo que é dentro da sociedade, como resultado de processos sociais, que o indivíduo se torna uma pessoa, que leva adiante os vários projetos que constituem a sua vida (Berger, 1985). A cultura é uma teia de significados, teia a qual o homem tece e da qual necessita tanto para encontrar seus apoios no mundo (Geertz, 1989).

Assim, a valorização da cultura popular contribui para que a sociedade fortaleça a "individuação e a autoestima diante do outro", numa busca de desenvolvimento originário de sua própria criatividade e conforme os seus valores, porque é por intermédio da cultura que o indivíduo e a sociedade interagem com o mundo à sua volta (Kashimoto, Marinho \& Russeff, 2002, p. 36).

Anais do 9 Congresso Internacional de Design da Informação | CIDI 2019

Proceedings of the 9th Information Design International Conference

Anais do $9^{\circ}$ Congresso Nacional de Iniciação Científica em Design da Informação | CONGIC 2019

Proceedings of the $9^{\text {th }}$ Information Design Student Conference 


\section{Reisado}

Alguns estudiosos divergem sobre a origem histórica do Reisado praticado no Nordeste brasileiro. Costuma-se falar de origem europeia, ao mesmo tempo em que é perceptível a forte influência dos negros africanos nas manifestações populares existentes no nosso país. (Nunes, 2007, p. 97)

Barroso (2008) cita os diversos nomes para o Reisado, encontrados por todo o Brasil: Terno de Reis, Tiração de Reis, Folia de Reis, Reisado - de Congo, de Caretas ou de Couro, de Caboclos, de Bailes -, Boi, Rancho de Reis, Guerreiros, etc., sendo todos ao mesmo tempo rito, brincadeira de terreiro, cortejo de brincantes e teatro tradicional, com encenação da origem do mundo cristão popular, o nascimento do divino, com a participação ativa da comunidade, com diversas linguagens artísticas (música, teatro, dança, artes visuais - nos figurinos e adereços). Tradicionalmente, os Reisados no Ceará ocorrem nos períodos festivos, como Natal, Semana Santa, Renovações do Coração de Jesus (comemorações anuais, comum nas casas de devotos da região), e outras comemorações locais, e se desenvolvem em autos, com riqueza de detalhes, resultado da unificação de saberes popular e hábitos incorporados, combinando elementos épicos e cômicos.

A celebração religiosa realizada pelos grupos de Reisado carrega consigo a relação do sagrado com o profano. A devoção está entrelaçada com bater das espadas, a exaltação ao nascimento do Menino Jesus divide espaço com as zombarias do Mateus e a tentativa de arrecadação de dinheiro junto aos espectadores.

O tipo de Reisado é definido a partir da estrutura e de personagens que possui. Na região do Cariri é comum o Reisado de Congos, no qual apresenta uma estrutura composta por uma tropa de nobres guerreiros, chefiadas por um Mestre, com dois Mateus e uma Catirina, trazendo o cômico para o espetáculo. Temos também o Reisado de Bailes, onde o Mestre é um nobre ou fazendeiro, que constitui a base da brincadeira, reunindo em um baile, suas filhas e pretendentes, que formam o conjunto de Damas e Galantes. O Reisado de Couro ou Caretas, no qual baseia-se no conflito entre Amo (Patrão ou Capitão) e os Caretas (seus moradores); seus trajes se caracterizam por batas ou vestidos largos e compridos, e utilizam máscaras dos mais diferentes materiais, carregando chocalhos e chicotes, saem pelas ruas em grupos, fazendo grande algazarra, mexendo com as pessoas e assustando as crianças. É comum a apresentação dos Caretas junto ao Reisado de Congos e Reisado de Baile (Barroso, 2008).

Os personagens ou brincantes (integrantes) do Reisado de Congo, compõem um coletivo composto por Rei, Mestre, Contramestre, dois Embaixadores, dois Guias, dois Contra-guias, dois Coices, dois Contra-coice, quatro figurinhas (também chamado de Marujos ou Romeirinhos), dois Mateus, a Rainha e a Catirina. Em suas apresentações realizam os bailados (peças cantadas e dançadas), composto por Marcha em Cortejo, Abertura de Porta, Entrada, Louvação ao Divino, "Entronamento" e "Destronamento" do Rei, execução de Peças e encenam uma série de entremezes ou "entremeios" (pequenas dramatizações), comédias do Mateus, encenação de Embaixadas e Batalhas, Despedida. Os entremezes mais comuns são: O Boi, a Burrinha, o Jaraguá, a Catirina, entre outros. Essas figuras, entremezes, peças e embaixadas variam entre os grupos e o local o qual pertencem.

Detalhando as figuras mais comuns, temos: o REI, criança ou adulto que durante a apresentação senta em seu trono, representado por uma cadeira; o MESTRE, quem dirige o espetáculo, tira as 'peças', conduz um apito que serve para chamar a atenção dos brincantes; o CONTRAMESTRE é quem substitui e dá apoio ao mestre; dois EMBAIXADORES, cada um liderando uma das fileiras; as FIGURAS, formam uma espécie de coro, que dança, canta, joga espada, responde as chamadas do mestre e, eventualmente, participa de alguma encenação; a RAINHA, menina, usa um vestido comprido e uma coroa na cabeça, participa sentada em seu trono; o MATEUS como sua parceira CATIRINA, é um casal de negros espertos e atrevidos, auxiliam na organização do espaço e dos brincantes durante a apresentação, interagem com irreverência com participantes do reisado e do público. A vestimenta do reisado é quase

Anais do 9 Congresso Internacional de Design da Informação | CIDI 2019

Proceedings of the 9th Information Design International Conference

Anais do $9^{\circ}$ Congresso Nacional de Iniciação Científica em Design da Informação | CONGIC 2019

Proceedings of the $9^{\text {th }}$ Information Design Student Conference 
sempre colorida e brilhante, geralmente composta de saiote, camisa, colete, capa, capacete, espadas ou maracás, tênis e meião. Os coletes e capacetes são adornados por objetos refletivos (metal, espelhos, lantejoulas etc.) e fitas. O Mateus veste calça e camisa, ou macacão, a Catirina vestido, seus adornos são mais incrementados e com mais adereços (rosários, cintos, chapéus, colares, óculos etc.).

\section{Pictogramas}

Para Salema (2016, p.28), "os pictogramas são uma invenção moderna, que constituem um ramo particular dos sinais pictóricos". Como sinal, utilizados para comunicação, sua origem é estudada desde a escrita, na pré-história, seguido pelos primeiros sistemas de sinais - na Mesopotâmia, e os hieróglifos no Egito.

Esse sistema de comunicação não verbal surge com a intenção de ser uma linguagem acessível, independente social e culturalmente, capaz de ser entendida por diversos povos. Seu início deu-se na década de 1920 e continuou-se até 1940, e ainda hoje influenciam diversos trabalhos. O seu idealizador, Otto Neurath, foi também o grande propagador dessa linguagem, trabalhando para que fosse reconhecido e implantado (Salema, 2016). Junto com o artista gráfico alemão, Gerd Arntz (1900-1988), desenhou uma série de pictogramas, capaz de transmitir de forma simples e objetiva as informações desejadas.

O intuito era que eles fossem produzidos livres de informações desnecessárias, um sinal produzido sem a personalidade do designer.

Segundo Salema, desde o início da implantação do sistema ISOTYPE, alguns escritores e designers questionaram sobre sua objetividade, e da impossibilidade de se produzir uma linguagem universal e propuseram modelos que acentuassem a relatividade cultural das imagens.

Os pictogramas da Isotype foram logo integrados em espaços públicos e na indústria, seu legado inclui tanto desenhos de gráficos estatísticos como a produção generalizada de símbolos visuais associados desde o transporte de passageiros a identidade coorporativa; sua teoria da linguagem continua servindo de informação para a educação do design gráfico (Salema, 2016).

\section{Aspectos metodológicos ou o bailado}

Esse estudo tem por finalidade realizar uma pesquisa exploratória, uma vez que utilizará conhecimento da pesquisa básica para um melhor tratamento dos objetivos. Detectou-se também a necessidade da pesquisa bibliográfica na busca e alocação de conhecimento sobre o tema em questão, a fim de proporcionar uma melhor familiaridade com o mesmo.

A abordagem do tratamento da coleta de dados dispõe de pesquisas de campo, entrevistas, observações e contemplação de histórias orais, de modo a haver uma compreensão maior do público em estudo, e perceber sua realidade e limitações existentes.

Por se tratar de um projeto de natureza mais conceitual, o qual resultará em composições que poderão ser aplicadas em diversas superfícies, optamos por desenvolver nossa metodologia a partir da tríade de "análise", "síntese" e "avaliação". Estrutura norteadora de boa parte das metodologias, as quais se incluem as desenvolvidas por Bruce Archer, Morris Asimow por exemplo. O que orientou a estruturar esse projeto da seguinte maneira:

Análise: realizada através de uma pesquisa histórica do reisado no Cariri, bem como uma pesquisa iconográfica que guiou a síntese. Foi fundamental também a pesquisa sobre sinais e símbolos e sua relação com o design. Coletou-se também imagens de xilogravuras de José Marcionilio, artista da região, a fim de traçar elementos estéticos que definissem parâmetros para a composição. 
Figura 1: Xilogravura (usado com a permissão de Nilo)

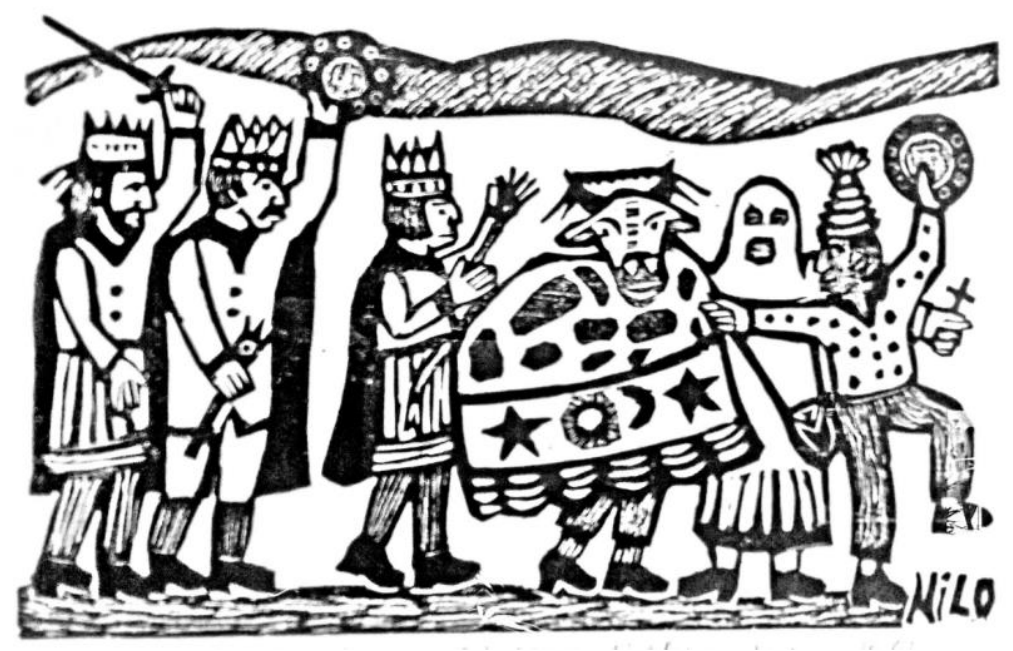

Síntese: a partir da coleta de imagens do reisado e das xilogravuras foram feitas experimentações, tentando em um primeiro momento definir a forma do traço que se utilizaria em todos os ícones.

Paralelo a esta etapa, seguiu-se o desenvolvimento de esboços, divididos em conjuntos previamente elencados do grupo de reisado, conforme sequência de imagens. A anatomia dos pictogramas foi baseada nas ilustrações do xilógrafo José Marcionilo (Nilo). 
Figura 2: Esboços e estudos para a construção de pictogramas

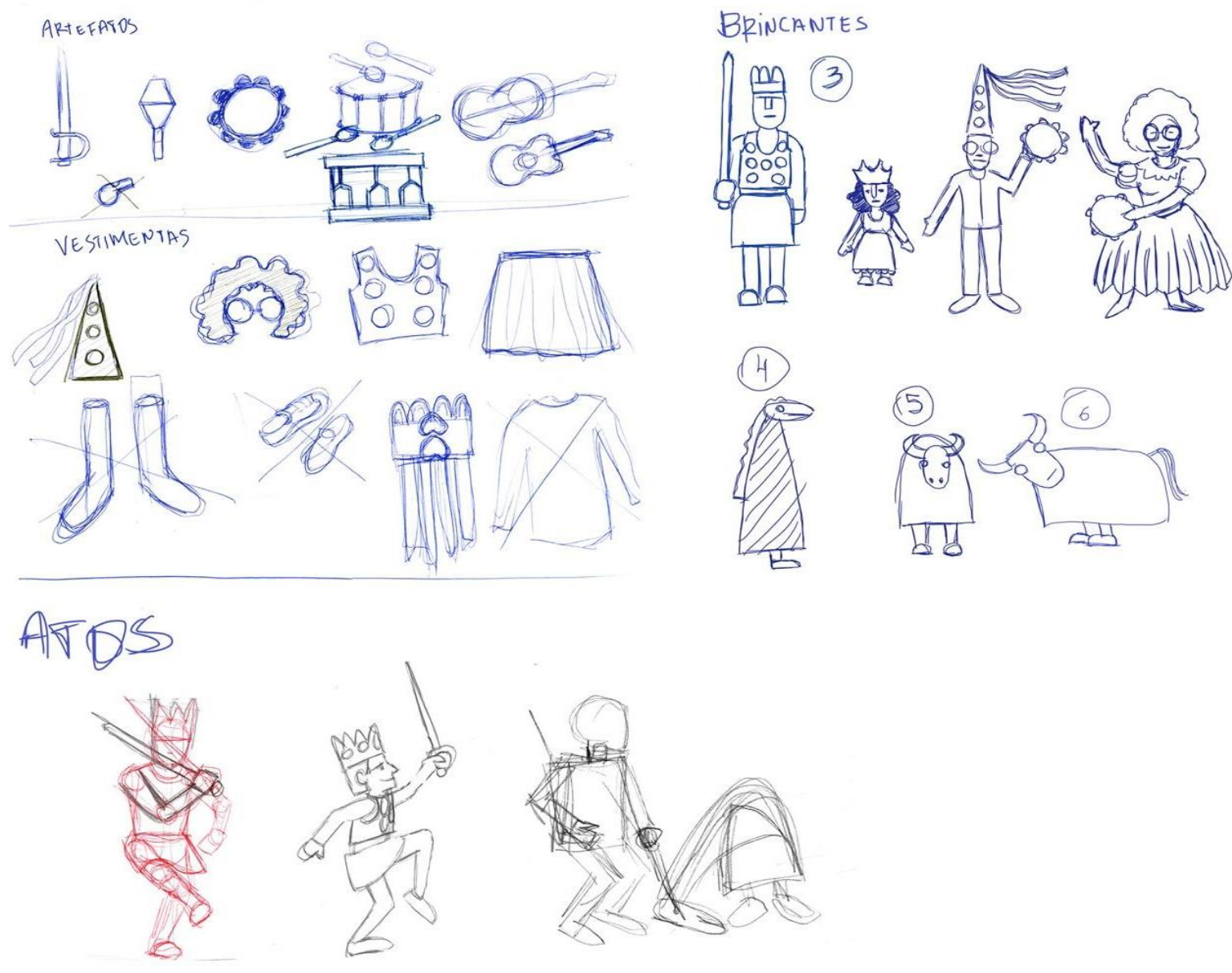

Figura 3: Anatomia dos pictogramas

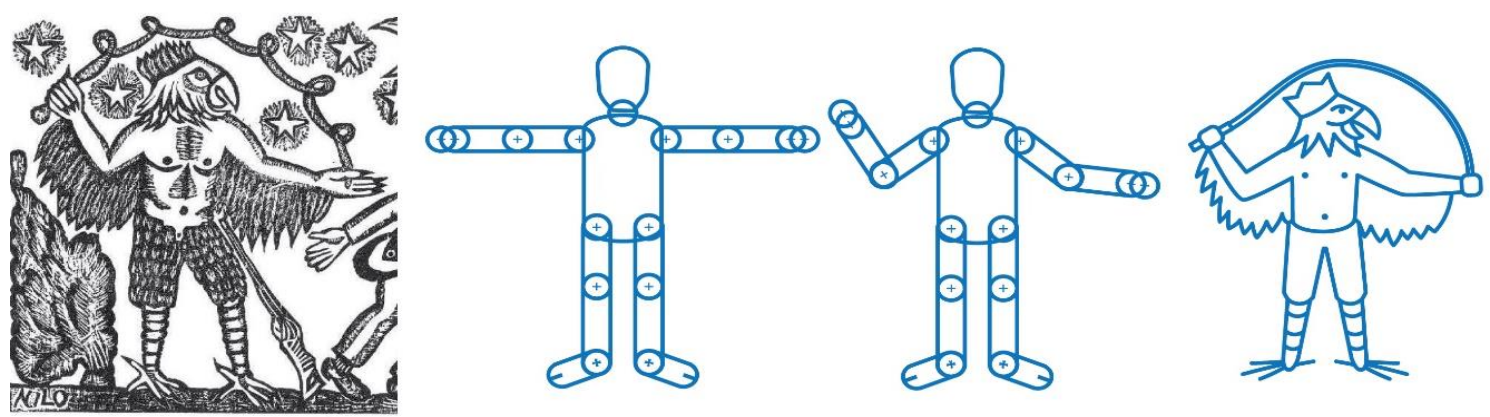

Anais do 9 Congresso Internacional de Design da Informação | CIDI 2019 
Avaliação: nesta fase a necessidade principal foi com a identificação dos pictogramas, se cumpre sua função informativa de forma simples e objetiva. Através de testes, inclusão e exclusão de elementos, escolha de posturas e composição chegou-se ao resultado esperado.

Na sequência, apresentamos a finalização dos pictogramas, seguidos de algumas possíveis aplicações. Para a aplicação, surgiu a necessidade de aplicação de texto, a qual optou-se por utilizar a tipografia "cratense", desenvolvida por uma colega do curso, a designer Lucélia Barbosa, inspiradas nas platibandas das casas do Cariri.

Figura 4: Resultado final dos pictogramas

artefatos

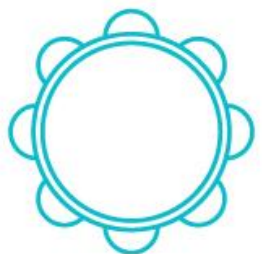<smiles>CC1CCCCC1</smiles><smiles>C=Cc1ccccc1</smiles>

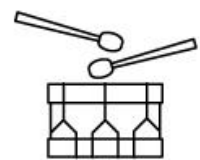<smiles>C=C1C2CCC1C2</smiles>
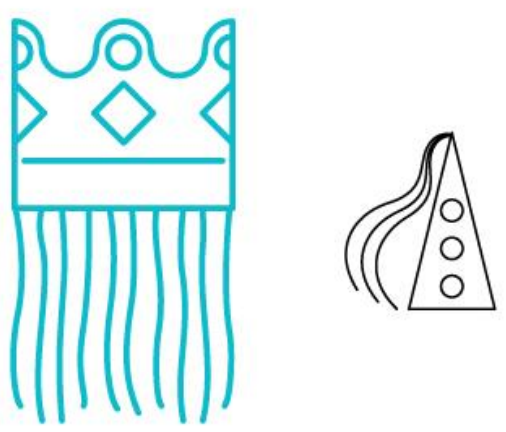

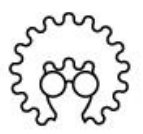
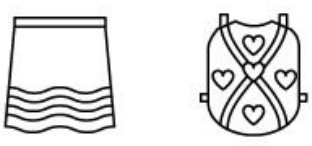

brincantes
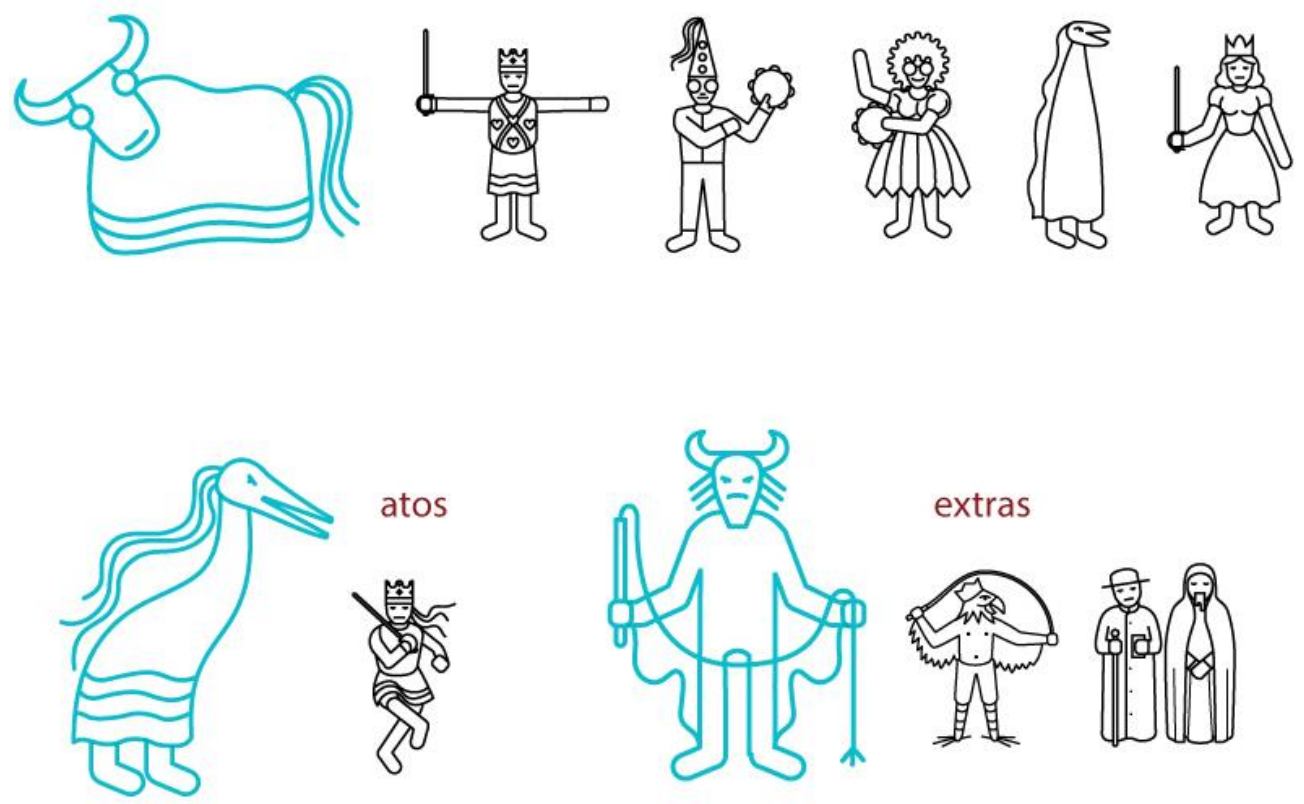

Anais do 9ํㅡㄹ Congresso Internacional de Design da Informação | CIDI 2019

Proceedings of the 9th Information Design International Conference

Anais do $9^{\circ}$ Congresso Nacional de Iniciação Científica em Design da Informação | CONGIC 2019

Proceedings of the $9^{\text {th }}$ Information Design Student Conference 
Silva, C. R. F. da,. Santos, D. R. dos. \& Araújo, M. D. X. de. | Figuras do baile: pictogramas para o fortalecimento da identidade dos grupos de reisado do Cariri

Figura 5: Estandarte construído a partir de elementos dos pictogramas
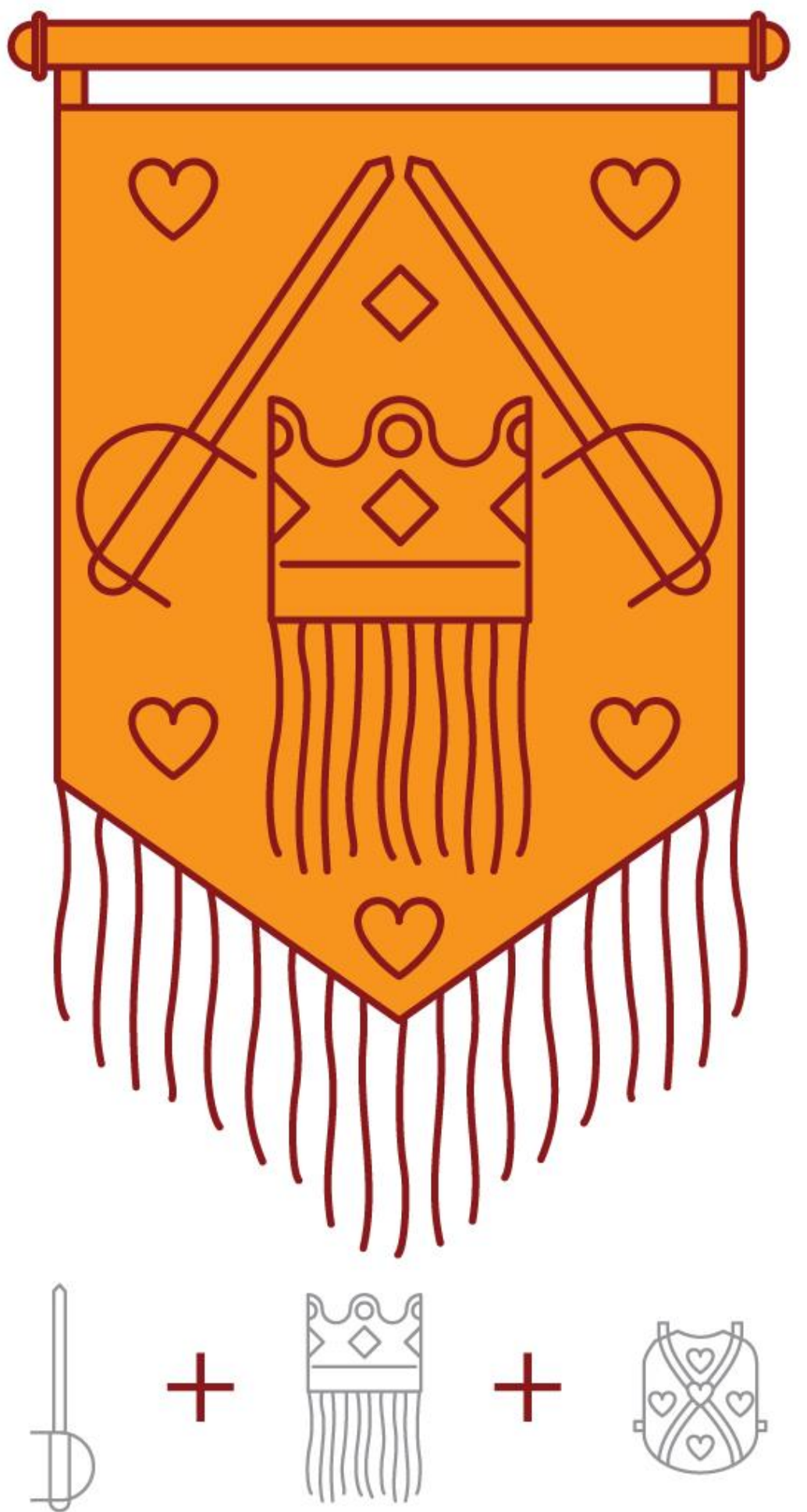

Anais do 9ํㅡㄹ Congresso Internacional de Design da Informação | CIDI 2019

Proceedings of the 9th Information Design International Conference

Anais do $9^{\circ}$ Congresso Nacional de Iniciação Científica em Design da Informação | CONGIC 2019

Proceedings of the $9^{\text {th }}$ Information Design Student Conference 
Silva, C. R. F. da,. Santos, D. R. dos. \& Araújo, M. D. X. de. | Figuras do baile: pictogramas para o fortalecimento da identidade dos grupos de reisado do Cariri

Figura 6: Identificação de casa de mestres e brincantes do reisado

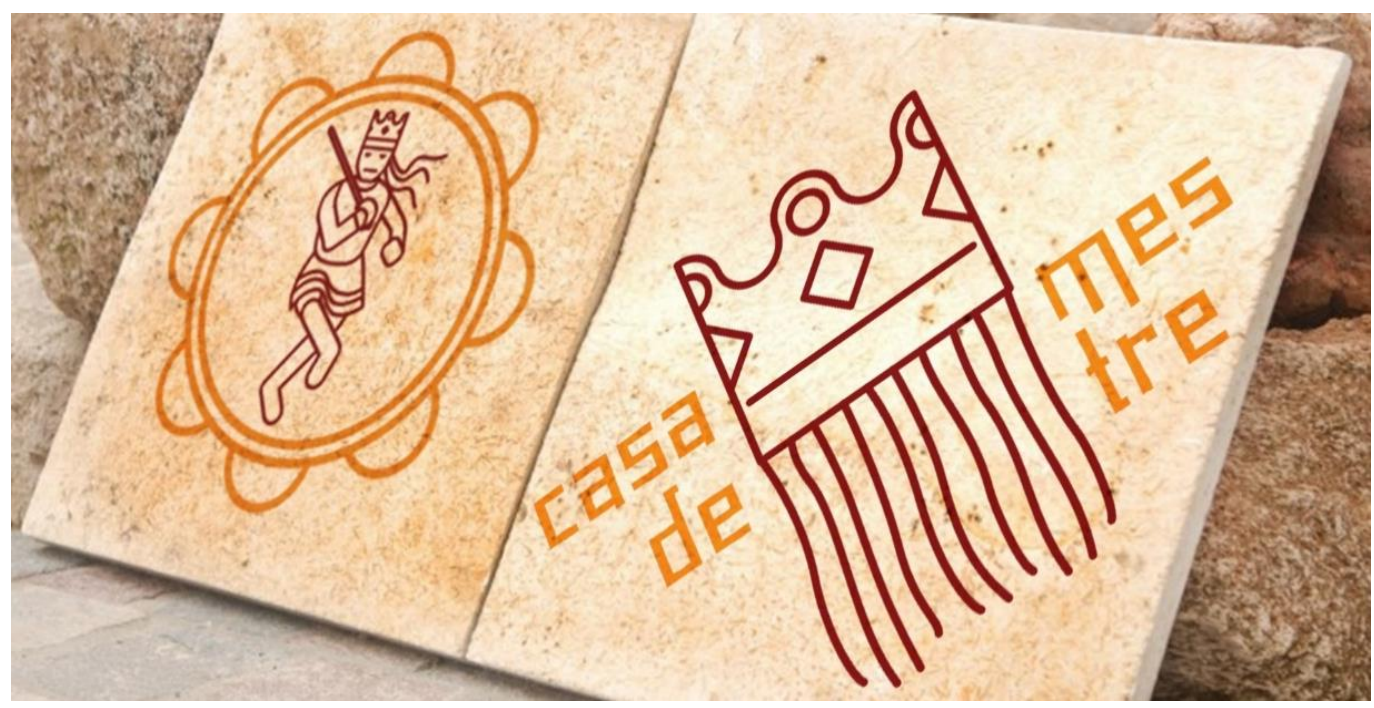

Figura 7: Possibilidade de utilização para sinalização de ruas e espaços de ensaios

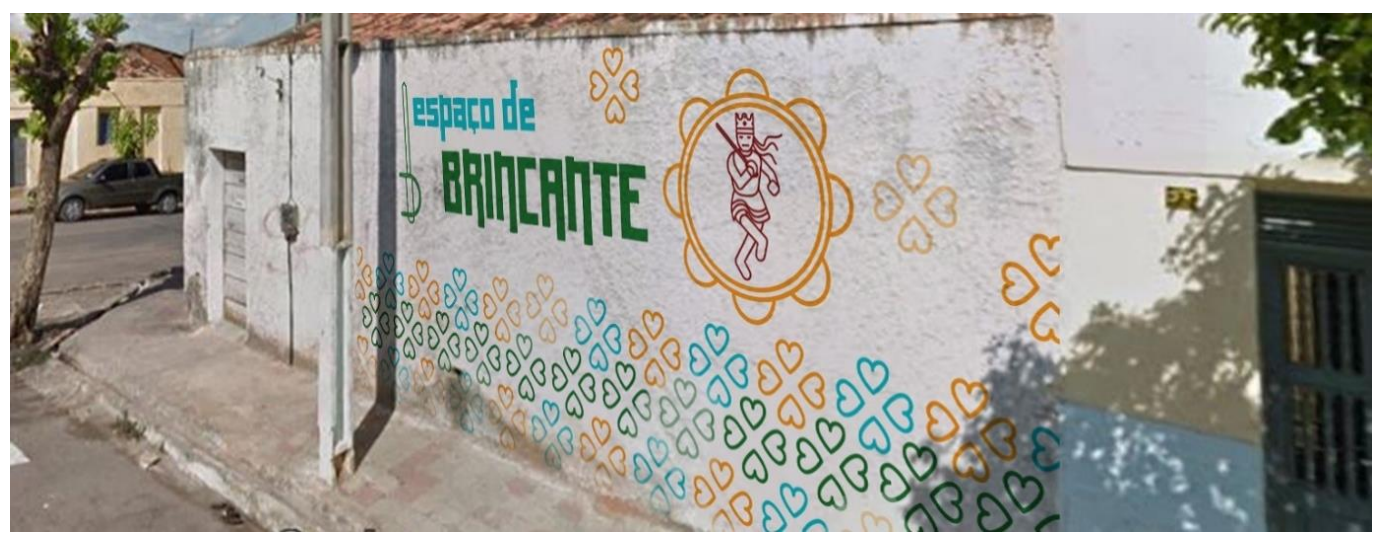

Figura 8: Sinalização de instituições

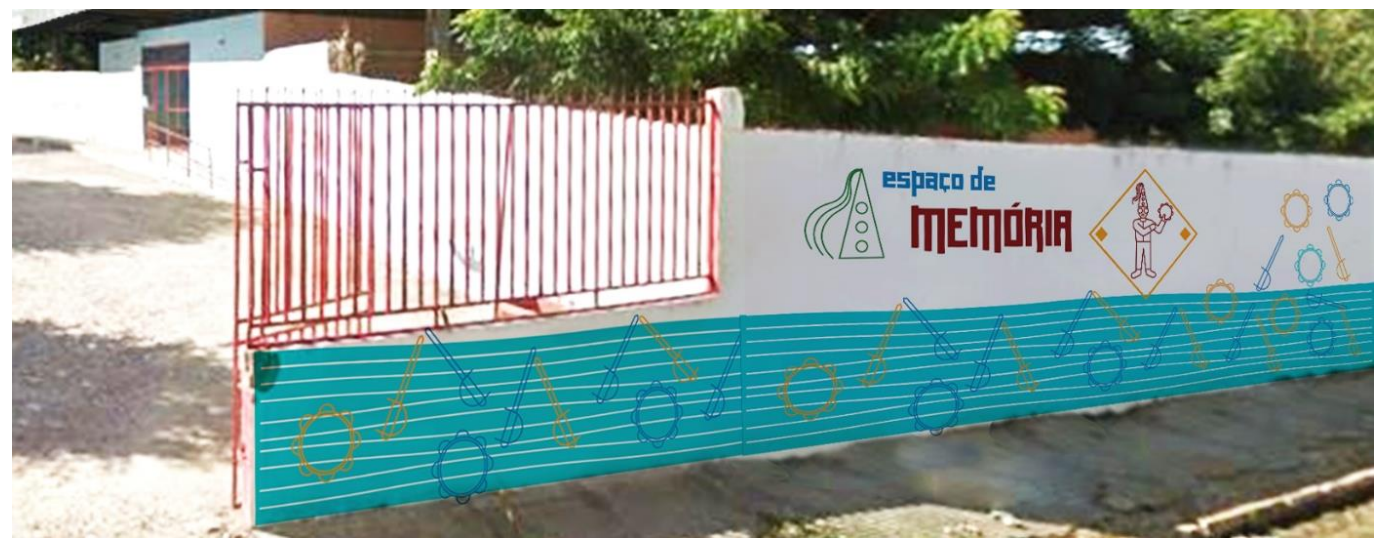

Anais do 9o Congresso Internacional de Design da Informação | CIDI 2019

Proceedings of the 9th Information Design International Conference

Anais do $9^{\circ}$ Congresso Nacional de Iniciação Científica em Design da Informação | CONGIC 2019

Proceedings of the $9^{\text {th }}$ Information Design Student Conference 


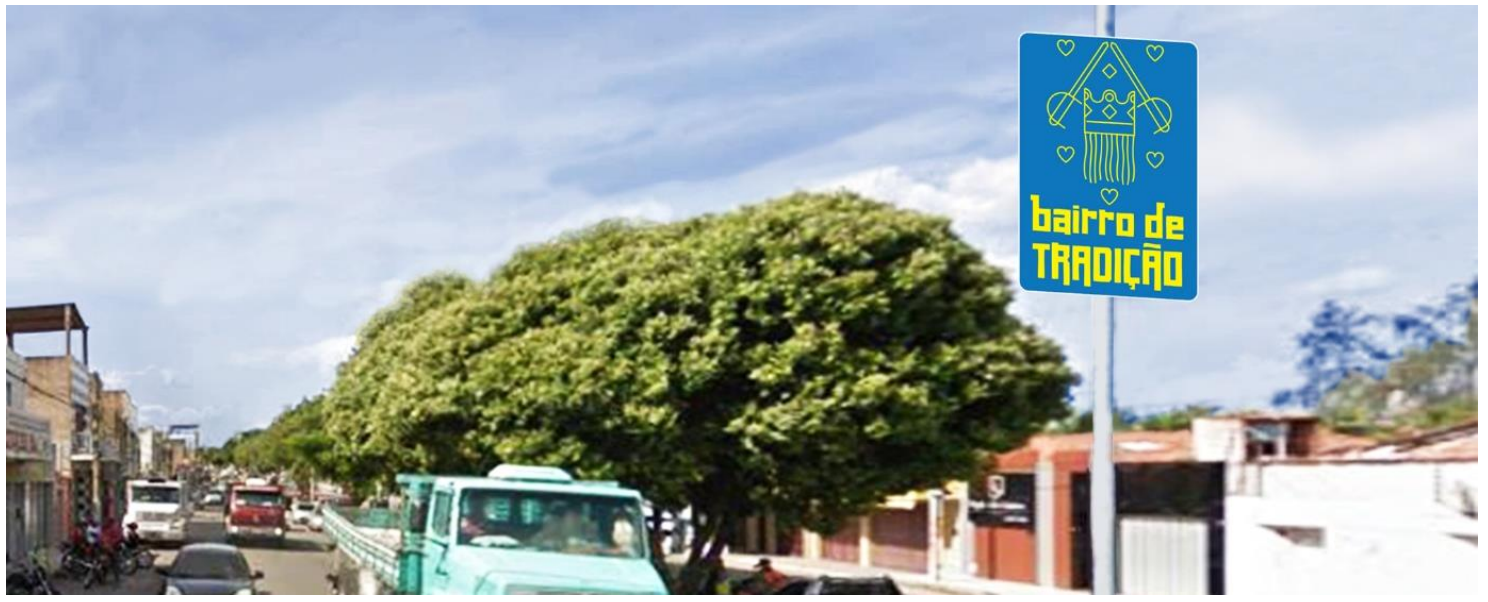

\section{Considerações finais ou despedida}

Como a memória, ainda repleta das lembranças da infância, percebendo uma carência identitária para divulgação e valorização dos grupos de reisado, busquei contribuir, com a construção de pictogramas, para dar maior visibilidade aos mesmos. Por sua facilidade de leitura, os pictogramas são utilizados, em sua maioria, na sinalização de espaços públicos e privados e na propagação de informações de forma simples e objetiva. Sua aplicabilidade na divulgação dos grupos pode ser empregada em produtos (vestimentas, instrumentos e objetos) sinalização de bairros, ruas, espaços e material informativo (cartazes, divulgação em mídias digitais).

Na pretensão de fortalecer a identidade dos grupos de tradição, os pictogramas desenvolvidos tornam-se apenas um pano de fundo para que possa destacar a memória e identidade dos mestres, que trazem sua realeza e maestria para o cotidiano da vida, valorizando sua comunidade, seus guerreiros/brincantes, preservando a tradição e valores ancestrais de sua cultura.

\section{Referências}

Barros, J.A. (2007). Cidade e História. Petrópolis. RJ: Vozes.

Barros, L.O.C. (2001). Santuários, Peregrinações e Novas Modalidades de Concentrações Humanas nas Práticas Religiosas. Diálogos Latinoamericanos, n.3, Universidade de Aarhus. Aarhus, Latinoamericanistas, pp. 147-154.

Barroso, Oswald. (1997) Reis de Congo - Teatro Popular tradicional. Fortaleza, CE, Minc/Flacso/MIS. Banco do Nordeste.

(2008) Reisado: Um Patrimônio da Humanidade. Juazeiro do Norte:

Berger, P. L. (1985). O dossel sagrado: elementos para uma teoria sociológica da religião. São Paulo: Paulus.

Cava, R. D. (1985). Milagre em Joaseiro. Rio de Janeiro: Editora Paz e Terra.

Anais do 9o Congresso Internacional de Design da Informação | CIDI 2019

Proceedings of the 9th Information Design International Conference

Anais do $9^{\circ}$ Congresso Nacional de Iniciação Científica em Design da Informação | CONGIC 2019

Proceedings of the $9^{\text {th }}$ Information Design Student Conference 
Geertz, C. (1989). A interpretação das culturas. Rio de Janeiro: LT\&C.

Kashimoto, E. M., Marinho, M., \& Russeff, I. (2002). Cultura, Identidade e Desenvolvimento Local: conceitos e perspectivas para regiões em desenvolvimento. Revista Internacional de Desenvolvimento Local, 3(4), pp.35-42.

Laraia, R. B. (2006). Cultura: Um conceito antropológico. 19. Ed. Rio de Janeiro: Jorge Zahar.

Lopez, F. (2016). Projeto MiniRio. Rio de Janeiro. Disponível em: <www.minirio.com.br>. Acessado em: 27/jul/2016.

Morigi, V. J., Rocha, C. P. V., \& Semensatto, S. (2012). Memória, representações sociais e cultura imaterial. Morpheus, Rio de Janeiro, 14.

Nunes, C. (2007). O Reisado em Juazeiro do Norte - CE e os conteúdos da História e Cultura Africana e Afrodescendente: uma proposta para a implementaçãi da Lei № 10.639/03. Dissertação. Universidade Federal do Ceará - UFC. Fortaleza, 2007. Disponível em: < http://www.repositorio.ufc.br/bitstream/riufc/2982/1/2007_dis_CNunes.pdf>. Acessado em: 10/out/2017.

Ramos, F. R. L. (2000). Padre Cícero. Edições Demócrito Rocha, Fortaleza/Ce.

Salema, M. (2016). Infografia na cozinha: o processo de simplificação do livro de receitas. Dissertação. Escola Superior de Artes e Design de Caldas da Rainha, 2016. Disponível em: <http://hdl.handle.net/10400.8/2451 >. Acessado em: 15/abr/2018.

\section{Sobre o(a/s) autor(a/es)}

Cicero Reginaldo Farias da Silva, Tecnólogo em Design de Produto, UFCA, Brasil

$<$ reginaldofariass@gmail.com>

Débora Rodrigues dos Santos, Tecnóloga em Design de Produto, UFCA, Brasil $<$ debora.proj@gmail.com>

Manoel Deisson Xenofonte de Araújo, Mestre em Design, Tecnologia e Cultura, UFCA, Brasil <deisson.araujo@ufca.edu.br> 